\title{
Madeiras históricas em embarcações tradicionais do baixo rio São Francisco
}

\author{
João Carlos Ferreira de Melo Júnior" \\ Cláudia Franca de Barros*
}

\begin{abstract}
MELO JÚNIOR, J.C.F.; BARROS, C.F. Madeiras históricas em embarcações tradicionais do baixo rio São Francisco. R. Museu Arq. Etn., 28: 109-123, 2017.
\end{abstract}

Resumo: Embarcações tradicionais estão diretamente ligadas à história do rio São Francisco e de suas comunidades ribeirinhas, sendo este um dos maiores rios navegáveis que permitiram a colonização da região Nordeste do Brasil. Este estudo objetivou conhecer as madeiras utilizadas na construção de embarcações do baixo rio São Francisco, gerando subsídios para melhor compreender as relações de uso de recursos florestais destinados à carpintaria naval tradicional. Foram estudadas quatro embarcações pertencentes ao acervo do Museu Nacional do Mar, São Francisco do Sul, Santa Catarina. A coleta das madeiras históricas foi realizada com auxílio de trado de incremento para posterior produção de lâminas histológicas e descrição anatômica. A identificação das madeiras foi realizada por comparação com coleção de referência. Foram identificadas onze espécies de madeiras usadas de forma mista na construção dos componentes das embarcações. São elas: Apuleia leiocarpa (Fabaceae), Astronium graveolens (Anacardiaceae), Brosimum gaudichaudii (Moraceae), Dalbergia nigra (Fabaceae), Hymenaea courbaril (Fabaceae), Manilkara dardanoi (Sapotaceae), Myracrodruon urundeuva (Anacardiaceae), Paubrasilia echinata (Fabaceae), Sextonia rubra (Lauraceae), Tabebuia aurea (Bignoniaceae) e Terminalia glabrencens (Combretaceae). O conhecimento sobre as madeiras e seu emprego tecnológico imprimem à construção de embarcações tradicionais um rico significado cultural que integra pessoas e árvores na paisagem do rio São Francisco.

Palavras-chave: Patrimônio cultural; Patrimônio naval; Anatomia da madeira; Recursos florestais; Velho Chico.

\section{Introdução}

patrimônio naval brasileiro é
representado por uma enormidade de tipologias de embarcações tradicionais confeccionadas pelas mãos de hábeis artesãos e por meio de diferentes técnicas herdadas dos povos indígenas, açorianos, ingleses e holandeses, tal qual o conhecimento da finalidade de embarcação, do tipo de propulsão e da área de navegação. Couto (1985) registra cerca de 36 tipos de embarcações tradicionais características das costas norte, nordeste, leste e sul do Brasil, dentre as quais destacam-se as famosas canoas do rio São Francisco.

\footnotetext{
** Doutorado em Ciências Biológicas (Biofísica) pela Universidade Federal do Rio de Janeiro. Pesquisadora do Instituto de Pesquisas Jardim Botânico do Rio de Janeiro.
} <cbarrosjbrj@gmail.com> 
Também conhecido como velho Chico, o rio São Francisco é o quinto maior rio navegável do Brasil, com aproximadamente $3.180 \mathrm{~km}$ de comprimento e $645 \mathrm{mil} \mathrm{km}^{2}$ de bacia de drenagem, a qual cobre cerca de $7,6 \%$ do território nacional. Tem sua nascente na Serra da Canastra, no sudoeste estado de Minas Gerais (MG), e sua foz no oceano Atlântico, na divisa entre os estados de Sergipe (SE) e Alagoas (AL). Além desses estados, esse rio também drena áreas dos estados da Bahia (BA) e de Pernambuco (PE) (Godinho \& Godinho 2003). Ao percorrer esses cinco estados e 521 municípios, o rio São Francisco atravessa os biomas do Cerrado, da Caatinga e da Mata Atlântica (Kohler 2003). Com base no perfil longitudinal do rio, sua bacia é dividida em quatro segmentos: alto (da nascente até Pirapora/MG, com 630 km), médio (de Pirapora/MG até Remanso/BA, com 1.090 km), submédio (de Remanso/BA até Paulo Afonso/BA, com 686 km) e baixo (de Paulo Afonso/BA até a foz, com $274 \mathrm{~km}$ ) (Paiva 1982).

A navegação no velho Chico sempre foi feita, desde a sua descoberta em 1501 por Américo Vespúcio, com o uso de barcos a vapor e gaiolas (Kohler 2003). Por volta de 1875, surgem, nas proas das embarcações do médio São Francisco, as carrancas, uma espécie de ornamentação singular do artesanato regional, símbolo dos municípios de Juazeiro/BA e Petrolina/PE, composta por peças de olhos esbugalhados, misto de homem, com suas sobrancelhas arqueadas, e de animal, com sua expressão feroz e sua cabeleira, tipo juba leonina (Pardal 1979), tendo por finalidade proteger os barqueiros contra naufrágios e animais do rio (Souza \& Caldas 2009). Além do transporte de mercadorias, a pesca artesanal foi uma das atividades mais tradicionais no rio São Francisco, a qual forneceu, durante quase duzentos anos, peixes que abasteceram as populações ribeirinhas e os mercados das regiões Nordeste e Sudeste do país (Montenegro et al. 2001; Valencio et al. 2003). Ao longo do tempo, essas embarcações foram substituídas pelas canoas de tolda, de influência holandesa, que, por sua vez, foram progressivamente sumindo do rio, restando apenas canoas e botes a vela (Silva 2013).

Se as embarcações tradicionais estão ligadas à história do rio São Francisco e de suas comunidades tradicionais ribeirinhas, o uso da floresta está intimamente imbricado às relações de formação identitária dessas comunidades, uma vez que revela um conjunto de saberes sobre o uso e o manejo dos recursos naturais pelos mestres fazedores de canoas que atravessa o tempo e, por meio dele, adquire novos contornos e significados.

$\mathrm{Na}$ contramão dessa constatação, o patrimônio naval tradicional associado à paisagem do rio São Francisco é um segmento ameaçado do patrimônio brasileiro devido à perda significativa das embarcações tradicionais, o conhecimento humano a elas associadas, o saber sobre as matérias-primas extraídas das florestas e as suas técnicas de produção, em detrimento das novas tecnologias e materiais para a produção naval e, também, da própria degradação socioambiental do velho Chico (Museu Nacional do Mar 2008; Valencio et al. 2003).

Este estudo tem como objetivo identificar e descrever as madeiras utilizadas por mestres artesãos na construção de canoas tradicionais do baixo rio São Francisco, gerando subsídios para melhor compreender as relações de uso de recursos florestais destinados à carpintaria naval tradicional do Nordeste brasileiro.

\section{Material e métodos}

Os objetos históricos investigados são embarcações tradicionais da região Nordeste do Brasil que compõem a paisagem do baixo rio São Francisco (Fig. 1), pertencentes ao Museu Nacional do Mar, localizado no município costeiro de São Francisco do Sul, Santa Catarina, Brasil. Esse museu abriga a maior coleção naval tradicional da América latina.

A descoberta das espécies de madeiras históricas utilizadas na produção do patrimônio brasileiro é de extremo interesse histórico e arqueológico, mas inexistem protocolos oficiais de investigação de objetos culturais em madeira tombados em museus nacionais. No entanto, nas licenças para esse tipo de pesquisa expedidas pelo Instituto do Patrimônio Histórico e Artístico Nacional (Iphan), há o 
estabelecimento de critério para a coleta de amostras de madeira nos objetos culturais que limita esse procedimento à obtenção de uma amostra cilíndrica com dimensão máxima de $1 \mathrm{~cm}$ de altura $\times 0,4 \mathrm{~cm}$ de diâmetro $\left(1,26 \mathrm{~cm}^{3}\right)$ com o uso de trado de incremento.

Seguindo essa metodologia de amostragem, foi possível obter amostras de madeira estritamente necessárias e em locais não aparentes dos principais componentes das embarcações (casco, caverna, mastro, quilha, retranca e tabuado), tal qual a sua tipologia
(Fig. 2, Tabela 1). A nomenclatura adotada para tais componentes foi definida como: (1) casco, o corpo da embarcação; (2) caverna, a peça em forma de arco que dá forma ao casco da embarcação; (3) mastro, a peça circular colocada no plano diametral em direção vertical para a sustentação das velas; (4) quilha, a peça disposta em todo o comprimento do casco no plano diametral; (5) retranca, verga onde está presa a parte inferior da vela; e (6) tabuado, o conjunto de tábuas de madeira que revestem a parte do convés exposta ao tempo (Navios \& Portos 2016).

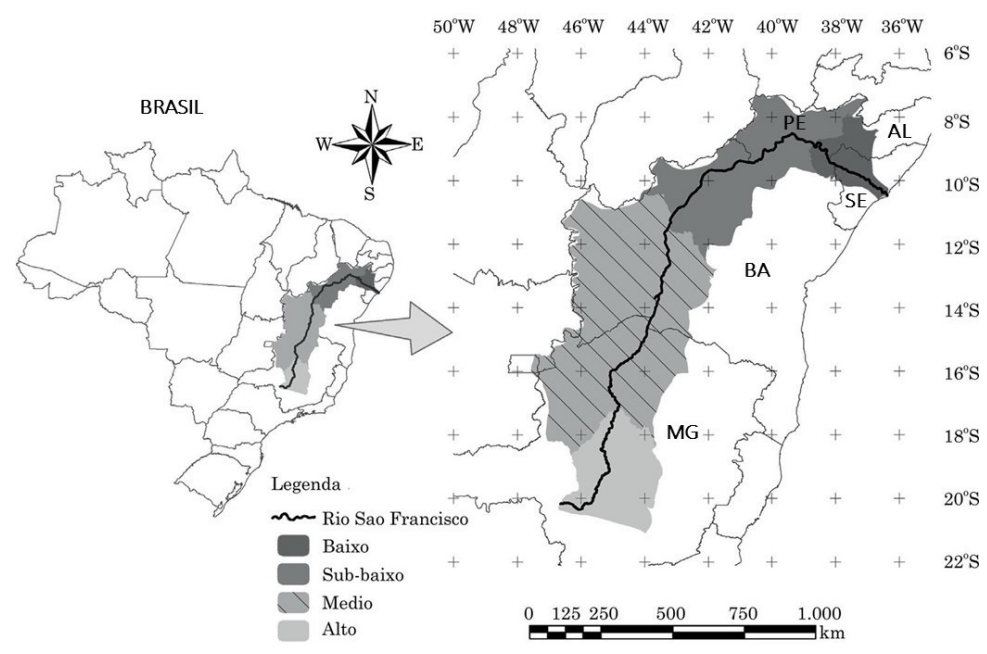

Fig. 1. Bacia hidrográfica do rio São Francisco, Nordeste do Brasil, e suas divisões. Fonte: Adaptado de Arruda, Schaefer \& Moraes 2015.

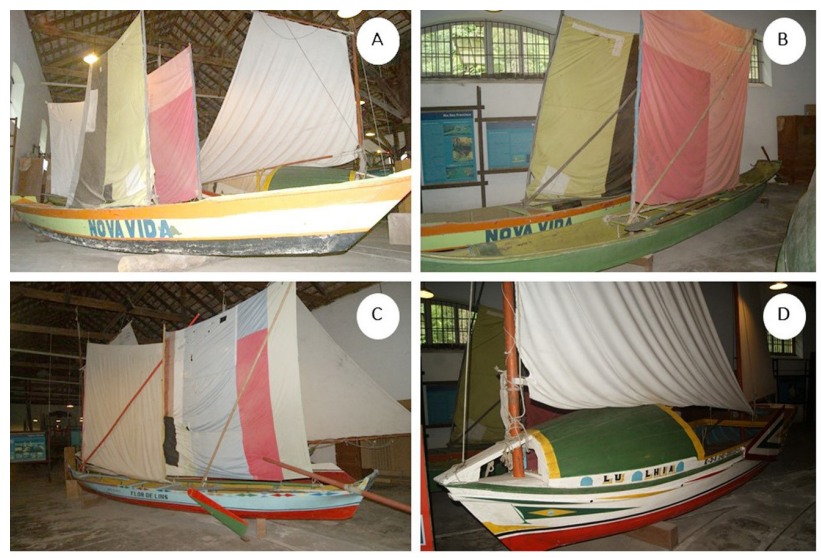

Fig. 2. Embarcações tradicionais do baixo rio São Francisco. 2A: Nova Vida. 2B: Sem título. 2C: Flor de Lins. 2D: Lu Lhia.

Fonte: Acervo do Museu Nacional do Mar (2010). 


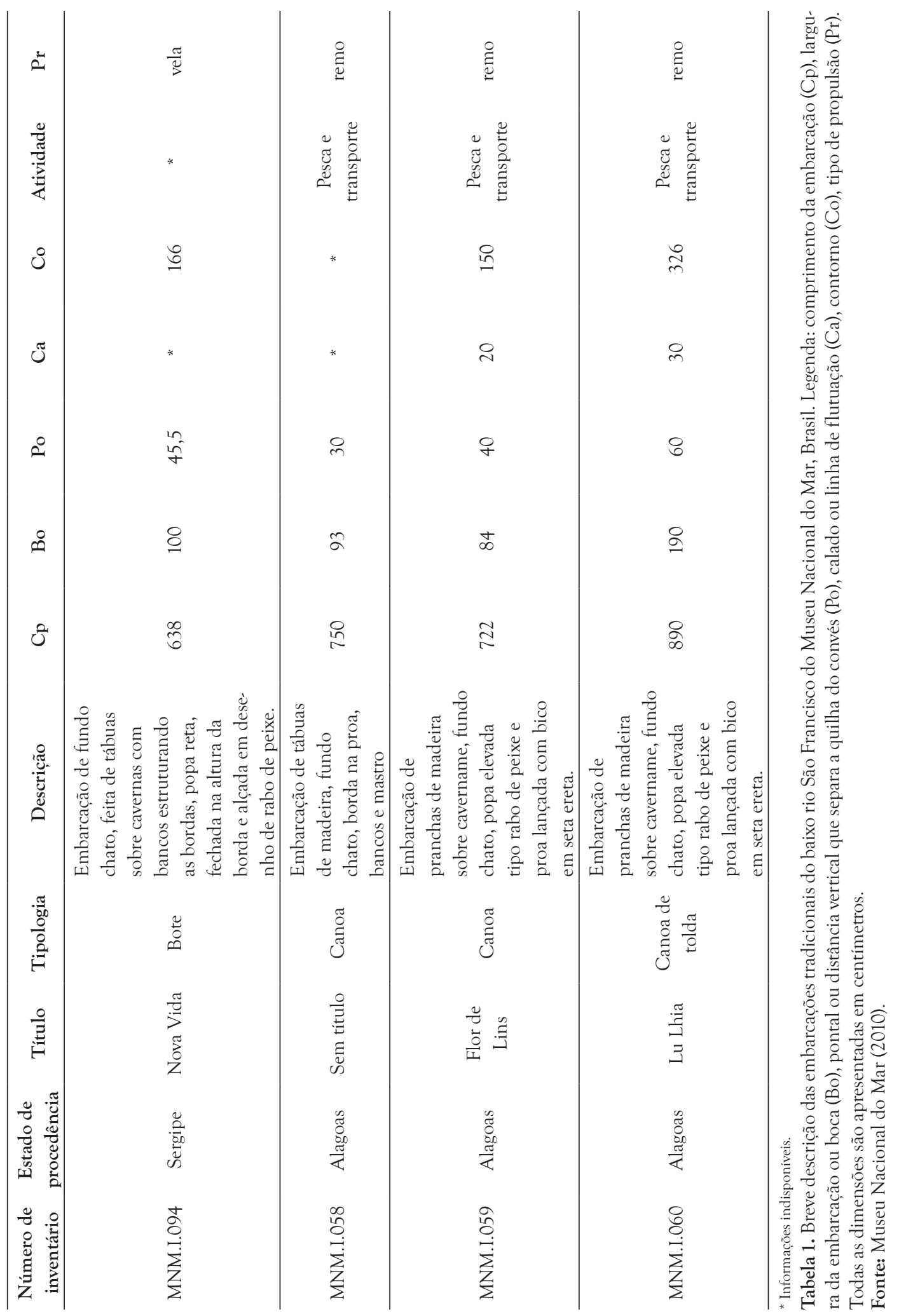


Os corpos de prova cilíndricos, muito friáveis à manipulação, foram amolecidos por cozimento e seccionados com lâmina de barbear nos planos convencionais para a anatomia da madeira. Os pequenos fragmentos obtidos foram, quando possivel, clarificados com hipoclorito de sódio, corados com safranina aquosa, desidratados em série alcoólica crescente, fixados em acetato de butila e montados em preparações permanentes com resina sintética do tipo verniz vitral (Kraus \& Arduin 1997; Paiva et al. 2006). Cortes histológicos extremamente quebradiços foram mantidos in natura para a montagem de lâminas permanentes.

As descrições anatômicas foram baseadas na terminologia proposta pelo Iawa Committee (1989). As características anatômicas observadas foram comparadas ao atlas de madeiras (Détienne \& Jacquet 1983), base de dados virtual Inside Wood (Wheeler 2011) e a coleção histológica de referência da xiloteca JOIw (Melo Júnior, Amorim \& Silveira 2014) para a identificação taxonômica.

\section{Resultados}

Foram identificadas onze diferentes espécies pertencentes a sete famílias botânicas: (1) Apuleia leiocarpa (Vogel) J.F.Macbr. (Fabaceae, amarelo); (2) Astronium graveolens Jacp. (Anacardiaceae, guaritá); (3) Brosimum gaudichaudii Trécul (Moraceae, conduru); (4) Dalbergia nigra (Vell.) Allemão ex Benth. (Fabaceae, caviuna); (5) Hymenaea courbaril L. (Fabaceae, jatai); (6) Manilkara dardanoi Ducke (Sapotaceae, maçaranduba); (7) Myracrodruon urundeuva Allemão (Anacardiaceae, aroeira); (8) Paubrasilia echinata (Lam.) E. Gagnon, H.C. Lima \& G.P. Lewis (Fabaceae, pau-d'arco); (9) Sextonia rubra (Mez) van der Werff (Lauraceae, lourorosa); (10) Tabebuia aurea (Silva Manso)

Benth. \& Hook.f. ex S.Moore (Bignoniaceae, ipê); e (11) Terminalia glabrencens Mart. (Combretaceae, pequi). A Tabela 2 exibe os principais caracteres anatômicos observados em cada espécie de madeira, e a Tabela 3 atribui a cada componente das embarcações estudadas as espécies identificadas. As Figuras 3 a 8 ilustram as características anatômicas de diagnose das espécies de madeira identificadas.

Aproximadamente $43 \%$ das amostras foram das madeiras de amarelo (A. leiocarpa), de caviúna (D. nigra) e de pequi (T. glabrescens). Dentre as famílias botânicas, houve prevalência no uso das madeiras de Fabaceae e Anacardiaceae, que representaram $86 \%$ das amostras. As demais madeiras tiveram uso único. Apesar de não ter sido observada uma relação direta entre determinada espécie de madeira e um componente da embarcação, devido à grande diversidade de espécies identificadas, a elevada densidade básica $(>0,72)$ é a propriedade física da madeira mais comum entre as amostras (Tabela 3 ), caracterizando-as como madeiras que variam de moderadamente pesadas a muito pesadas.

\begin{tabular}{|c|c|c|c|}
\hline $\begin{array}{c}\text { Espécie de } \\
\text { madeira }\end{array}$ & Seção transversal & Seção longitudinal tangencial & $\begin{array}{c}\text { Seção longitudinal } \\
\text { radial }\end{array}$ \\
\hline $\begin{array}{l}\text { Apuleia } \\
\text { leiocarpa }\end{array}$ & $\begin{array}{l}\text { Camadas de crescimento indistintas. } \\
\text { Porosidade difusa. Vasos na maioria } \\
\text { solitários, múltiplos radiais 2-4, raros } \\
\text { racemiformes. Diâmetro tangencial } \\
\text { de } 100-200 \mu \mathrm{m} \text {. Frequência de } 20 \text { - } \\
40 \text { vasos } / \mathrm{mm}^{2} \text {. Parênquima axial } \\
\text { paratraqueal vasicêntrico, aliforme, } \\
\text { aliforme-losangular, confluente em } \\
\text { trechos longos e em faixas com mais } \\
\text { de três células de largura. }\end{array}$ & $\begin{array}{l}\text { Fibras não septadas com paredes } \\
\text { finas. Séries parenquimáticas } \\
\text { compostas por } 2-4 \text { células. Raios } 1-2 \\
\text { seriados, heterogêneos, com corpo } \\
\text { formado por células procumbentes e } \\
\text { uma camada marginal de células ere- } \\
\text { tas ou quadradas. Elementos axiais } \\
\text { estratificados. }\end{array}$ & $\begin{array}{l}\text { Placa de perfuração } \\
\text { simples. Pontoaçôes } \\
\text { intervasculares } \\
\text { alternas e médias. } \\
\text { Corpos silicosos em } \\
\text { células do raio. }\end{array}$ \\
\hline
\end{tabular}




\begin{tabular}{|c|c|c|c|}
\hline $\begin{array}{l}\text { Espécie de } \\
\text { madeira }\end{array}$ & Seção transversal & Seção longitudinal tangencial & $\begin{array}{c}\text { Seção longitudinal } \\
\text { radial }\end{array}$ \\
\hline $\begin{array}{l}\text { Astronium } \\
\text { graveolens }\end{array}$ & $\begin{array}{l}\text { Camadas de crescimento distin- } \\
\text { tas, demarcadas por zona fibrosa. } \\
\text { Porosidade difusa. Vasos solitários, } \\
\text { múltiplos radiais } 2-5 \text {, racemiformes, } \\
\text { obstruídos por tilos. Diâmetro tan- } \\
\text { gencial de } 100-200 \mu \mathrm{m} \text {. Frequência } \\
\text { de } 5-20 \text { vasos } / \mathrm{mm}^{2} \text {. Parênquima axial } \\
\text { paratraqueal escasso e vasicêntrico. }\end{array}$ & $\begin{array}{l}\text { Fibras septadas com paredes muito } \\
\text { espessas. Séries parenquimáticas } \\
\text { compostas por 3-4 células ou mais. } \\
\text { Raios } 1-3 \text { seriados, heterogêneos, } \\
\text { com corpo formado por células } \\
\text { procumbentes e } 2-4 \text { camadas } \\
\text { marginais de células eretas ou } \\
\text { quadradas. Canais radiais presentes. }\end{array}$ & $\begin{array}{l}\text { Placa de perfuração } \\
\text { simples. Pontoações } \\
\text { intervasculares alter- } \\
\text { nas e médias. Cristais } \\
\text { prismáticos presentes } \\
\text { em células eretas e } \\
\text { quadradas do raio. } \\
\text { Cristais em tiloses. } \\
\end{array}$ \\
\hline $\begin{array}{l}\text { Brosimum } \\
\text { gaudichau- } \\
\text { dii }\end{array}$ & $\begin{array}{l}\text { Camadas de crescimento indistintas. } \\
\text { Porosidade difusa. Vasos na maioria } \\
\text { solitários e múltiplos radiais } 2-4 \text {. } \\
\text { Diâmetro tangencial de } 50-100 \mu \mathrm{m} \text {. } \\
\text { Frequência de } 20-40 \text { vasos } / \mathrm{mm}^{2} \text {. Pa- } \\
\text { rênquima axial paratraqueal escasso, } \\
\text { vasicêntrico, aliforme, unilateral e } \\
\text { confluente em trechos longos. }\end{array}$ & $\begin{array}{l}\text { Fibras não septadas com paredes } \\
\text { muito espessas. Séries parenquimáti- } \\
\text { cas compostas por } 8 \text { células ou mais. } \\
\text { Raios } 1-3 \text { seriados, heterogêneos, } \\
\text { com corpo formado por células pro- } \\
\text { cumbentes e } 2-4 \text { camadas marginais } \\
\text { de células eretas ou quadradas. }\end{array}$ & $\begin{array}{l}\text { Placa de perfuração } \\
\text { simples. Pontoações } \\
\text { intervasculares } \\
\text { alternas e diminutas. } \\
\text { Cristais prismáticos } \\
\text { ausentes. }\end{array}$ \\
\hline $\begin{array}{l}\text { Dalbergia } \\
\text { nigra }\end{array}$ & $\begin{array}{l}\text { Camadas de crescimento distintas, } \\
\text { demarcadas por parênquima mar- } \\
\text { ginal. Porosidade difusa. Vasos na } \\
\text { maioria solitários e múltiplos radiais } \\
2-6 \text {, obstruídos por gomas ou outros } \\
\text { depósitos no lenho tardio. Diâmetro } \\
\text { tangencial de } 100-200 \mu \mathrm{m} \text {. Frequ- } \\
\text { ência }<5 \text { vasos } / \mathrm{mm}^{2} \text {. Parênquima } \\
\text { axial apotraqueal difuso e difuso } \\
\text { em agregado, paratraqueal escasso, } \\
\text { vasicêntrico, aliforme, unilateral, } \\
\text { confluente e faixas com mais de três } \\
\text { células de largura. }\end{array}$ & $\begin{array}{l}\text { Fibras não septadas com } \\
\text { paredes finas a espessas. Séries } \\
\text { parenquimáticas compostas por } \\
2 \text { células. Raios } 1-3 \text { seriados, } \\
\text { heterogêneos, com corpo formado } \\
\text { por células procumbentes e uma } \\
\text { camada marginal de células eretas ou } \\
\text { quadradas. Raios estratificados. }\end{array}$ & $\begin{array}{l}\text { Placa de perfuração } \\
\text { simples. Pontoações } \\
\text { intervasculares } \\
\text { alternas, médias } \\
\text { e guarnecidas. } \\
\text { Cristais prismáticos } \\
\text { em câmaras do } \\
\text { parênquima axial. }\end{array}$ \\
\hline $\begin{array}{l}\text { Hymenaea } \\
\text { courbaril }\end{array}$ & $\begin{array}{l}\text { Camadas de crescimento indistintas. } \\
\text { Porosidade difusa. Vasos na maioria } \\
\text { solitários e múltiplos radiais } 2 \text {-3. Diâ- } \\
\text { metro tangencial }>200 \mu \mathrm{m} \text {. Frequên- } \\
\text { cia }<5 \text { vasos } / \mathrm{mm}^{2} \text {. Parênquima axial } \\
\text { paratraqueal vasicêntrico, aliforme, } \\
\text { aliforme-losangular, aliforme-linear e } \\
\text { confluente. }\end{array}$ & $\begin{array}{l}\text { Fibras não septadas com paredes } \\
\text { finas a espessas. Séries parenquimáti- } \\
\text { cas compostas por 5-8 células. Raios } \\
\text { 4-10 seriados, homogêneos, com } \\
\text { corpo formado por células. }\end{array}$ & $\begin{array}{l}\text { Placa de perfuração } \\
\text { simples. Pontoações } \\
\text { intervasculares } \\
\text { alternas, grandes e } \\
\text { guarnecidas. Cristais } \\
\text { prismáticos em câ- } \\
\text { maras do parênqui- } \\
\text { ma axial. }\end{array}$ \\
\hline $\begin{array}{l}\text { Manilkara } \\
\text { dardanoi }\end{array}$ & $\begin{array}{l}\text { Camadas de crescimento indistintas. } \\
\text { Porosidade difusa. Vasos na maioria } \\
\text { múltiplos radiais } 2-5 \text {. Diâmetro } \\
\text { tangencial de } 100-200 \mu \mathrm{m} \text {. Frequ- } \\
\text { ência de } 20-40 \text { vasos } / \mathrm{mm}^{2} \text {. Parên- } \\
\text { quima axial em linhas } 1-3 \text { células e } \\
\text { reticulado. }\end{array}$ & $\begin{array}{l}\text { Fibras não septadas com paredes } \\
\text { finas a espessas. Séries parenquimáti- } \\
\text { cas compostas por } 5-8 \text { células. Raios } \\
1-3 \text { seriados, heterogêneos, com } \\
\text { corpo formado por células procum- } \\
\text { bentes e 2-4 camadas marginais de } \\
\text { células eretas ou quadradas. Raios } \\
\text { localmente unisseriados. }\end{array}$ & $\begin{array}{l}\text { Placa de perfuração } \\
\text { simples. Pontoações } \\
\text { intervasculares } \\
\text { alternas e pequenas. } \\
\text { Cristais prismáticos } \\
\text { em células do parên- } \\
\text { quima axial. }\end{array}$ \\
\hline $\begin{array}{c}\text { Myra- } \\
\text { crodruon } \\
\text { urundeuva }\end{array}$ & $\begin{array}{l}\text { Camadas de crescimento indistintas. } \\
\text { Porosidade difusa. Vasos na maioria } \\
\text { solitários, múltiplos radiais } 2 \text {, obstruí- } \\
\text { dos por tilos. Diâmetro tangencial } \\
\text { de } 100-200 \mu \mathrm{m} \text {. Frequência de } 5-20 \\
\text { vasos } / \mathrm{mm}^{2} \text {. Parênquima axial para- } \\
\text { traqueal escasso. }\end{array}$ & $\begin{array}{l}\text { Fibras não septadas com paredes mui- } \\
\text { to espessas. Séries parenquimáticas } \\
\text { compostas por } 5-8 \text { células. Raios } 1-3 \\
\text { seriados, heterogêneos, com corpo } \\
\text { formado por células procumbentes } \\
\text { e } 2-4 \text { camadas marginais de células } \\
\text { eretas ou quadradas. Canais radiais } \\
\text { presentes. }\end{array}$ & $\begin{array}{l}\text { Placa de perfuração } \\
\text { simples. Pontoações } \\
\text { intervasculares alter- } \\
\text { nas e médias. Cristais } \\
\text { prismáticos presentes } \\
\text { em células eretas e } \\
\text { quadradas do raio. } \\
\text { Cristais em células } \\
\text { enlanguescidas. }\end{array}$ \\
\hline
\end{tabular}




\begin{tabular}{|c|c|c|c|}
\hline $\begin{array}{l}\text { Espécie de } \\
\text { madeira }\end{array}$ & Seção transversal & Seção longitudinal tangencial & $\begin{array}{c}\text { Seção longitudinal } \\
\text { radial }\end{array}$ \\
\hline $\begin{array}{c}\text { Paubrasilia } \\
\text { echinata }\end{array}$ & $\begin{array}{l}\text { Camadas de crescimento indistintas. } \\
\text { Porosidade difusa. Vasos solitários } \\
\text { e múltiplos radiais } 2-4 \text { obstruídos } \\
\text { por óleo-resina. Diâmetro tangen- } \\
\text { cial de } 50-100 \mu \mathrm{m} \text {. Frequência de } \\
20-40 \text { vasos } / \mathrm{mm}^{2} \text {. Parênquima axial } \\
\text { paratraqueal vasicêntrico, aliforme, } \\
\text { aliforme-losangular, confluente e em } \\
\text { bandas marginais. }\end{array}$ & $\begin{array}{l}\text { Fibras não septadas com paredes } \\
\text { finas a espessas. Séries parenquimá- } \\
\text { ticas compostas por } 2 \text { células. Raios } \\
1 \text {-3 seriados, homogêneos, formados } \\
\text { apenas por células procumbentes. }\end{array}$ & $\begin{array}{l}\text { Placa de perfuração } \\
\text { simples. Pontoações } \\
\text { intervasculares } \\
\text { alternas, pequenas, } \\
\text { guarnecidas. Ponto- } \\
\text { ações raio-vasculares } \\
\text { com bordas distintas } \\
\text { e similares às inter- } \\
\text { vasculares. Cristais } \\
\text { prismáticos em } \\
\text { câmaras subdividi- } \\
\text { das do parênquima } \\
\text { axial. }\end{array}$ \\
\hline $\begin{array}{c}\text { Sextonia } \\
\text { rubra }\end{array}$ & $\begin{array}{l}\text { Camadas de crescimento indistintas. } \\
\text { Porosidade difusa. Vasos na maioria } \\
\text { múltiplos radiais } 2 \text {, raros solitários, } \\
\text { obstruídos por tilos. Diâmetro tan- } \\
\text { gencial de } 100-200 \mu \text { m. Frequência } \\
\text { de } 5-20 \text { vasos } / \mathrm{mm}^{2} \text {. Parênquima axial } \\
\text { paratraqueal escasso e vasicêntrico. }\end{array}$ & $\begin{array}{l}\text { Fibras não septadas com paredes } \\
\text { finas a espessas. Séries parenquimáti- } \\
\text { cas compostas por } 5-8 \text { células. Raios } \\
\text { 1-3 seriados, heterogêneos, com } \\
\text { corpo formado por células procum- } \\
\text { bentes e uma camada marginal de } \\
\text { células eretas ou quadradas. }\end{array}$ & $\begin{array}{l}\text { Placa de perfuração } \\
\text { simples. Pontoações } \\
\text { intervasculares } \\
\text { alternas e grandes. } \\
\text { Células oleíferas } \\
\text { ou mucilaginosas } \\
\text { associadas ao parên- } \\
\text { quima axial. }\end{array}$ \\
\hline $\begin{array}{c}\text { Tabebuia } \\
\text { aurea }\end{array}$ & $\begin{array}{l}\text { Camadas de crescimento indistintas. } \\
\text { Porosidade difusa. Vasos na maioria } \\
\text { solitários, raros múltiplos radiais } 2 \text {. } \\
\text { Diâmetro tangencial de } 50-100 \mu \mathrm{m} \text {. } \\
\text { Frequência de } 5-20 \text { vasos } / \mathrm{mm}^{2} \text {. Pa- } \\
\text { rênquima axial paratraqueal aliforme, } \\
\text { aliforme-losangular, confluente e } \\
\text { unilateral. }\end{array}$ & $\begin{array}{l}\text { Fibras não septadas com paredes } \\
\text { finas a espessas. Séries parenquimá- } \\
\text { ticas compostas por } 2 \text { células. Raios } \\
\text { uniseriados, homogêneos, com corpo } \\
\text { formado por células procumbentes. } \\
\text { Raios irregularmente estratificados. }\end{array}$ & $\begin{array}{l}\text { Placa de perfuração } \\
\text { simples. Pontoações } \\
\text { intervasculares alter- } \\
\text { nas e pequenas. }\end{array}$ \\
\hline $\begin{array}{l}\text { Terminalia } \\
\text { glabrencens }\end{array}$ & $\begin{array}{l}\text { Camadas de crescimento indistintas. } \\
\text { Porosidade difusa. Vasos solitários } \\
\text { e múltiplos radiais } 2-3 \text {. Diâmetro } \\
\text { tangencial de } 50-100 \mu \mathrm{m} \text {. Frequência } \\
\text { de } 5-20 \text { vasos } / \mathrm{mm}^{2} \text {. Obstrução de } \\
\text { gomas ou outros depósitos em raros } \\
\text { vasos do lenho tardio. Parênquima } \\
\text { axial paratraqueal vasicêntrico, } \\
\text { aliforme losangular, confluente em } \\
\text { trechos curtos. }\end{array}$ & $\begin{array}{l}\text { Fibras não septadas com paredes } \\
\text { finas a espessas. Séries parenqui- } \\
\text { máticas compostas por 5-8 células. } \\
\text { Raios exclusivamente unisseriados, } \\
\text { heterogêneos, formados apenas por } \\
\text { células quadradas e eretas. }\end{array}$ & $\begin{array}{l}\text { Placa de perfuração } \\
\text { simples. Pontoações } \\
\text { intervasculares } \\
\text { alternas, diminutas. } \\
\text { Pontoações raio-vas- } \\
\text { culares com bordas } \\
\text { distintas e similares } \\
\text { às intervasculares. } \\
\text { Cristais prismáticos } \\
\text { em células quadra- } \\
\text { das e eretas do raio. }\end{array}$ \\
\hline
\end{tabular}

Tabela 2. Características anatômicas usadas na identificação das espécies de madeira das embarcações tradicionais do baixo rio São Francisco.

Fonte: Elaborado pelos autores com base no acervo do Museu Nacional do Mar. 
Madeiras históricas em embarcações tradicionais do baixo rio São Francisco

R. Museu Arq. Etn., 28: 109-123, 2017.

\begin{tabular}{|c|c|c|c|}
\hline Título da embarcação & Componente & Espécie de madeira & $\begin{array}{c}\text { Densidade básica da } \\
\text { madeira }\left(\mathrm{g} . \mathrm{cm}^{-3}\right)\end{array}$ \\
\hline \multirow{4}{*}{ Nova vida } & caverna & Terminalia glabrencens & $0,81 \square$ \\
\hline & mastro & Brosimum gaudichaudii & $0,72 \circ$ \\
\hline & retranca & Terminalia glabrencens & $0,81 \square$ \\
\hline & tabuado & Paubrasilia echinata & $1,10 \diamond$ \\
\hline \multirow{3}{*}{ sem título } & casco & Sextonia rubra & $0,77 \boldsymbol{\Delta}$ \\
\hline & mastro & Apuleia leiocarpa & 0,83 - \\
\hline & quilha & Astronium graveolens & $0,97 \square$ \\
\hline \multirow{4}{*}{ Lu Lhia } & casco & Apuleia leiocarpa & 0,83 ш \\
\hline & caverna & Manilkara dardanoi & $1,00 \boldsymbol{\Delta}$ \\
\hline & mastro & Hymenaea courbaril & $0,96 \square$ \\
\hline & tabuado & Dalbergia nigra & 0,93 ш \\
\hline \multirow{3}{*}{ Flor de lins } & casco & Myracrodruon urundeuva & $1,19 \square$ \\
\hline & caverna & Dalbergia nigra & 0,93 ш \\
\hline & mastro & Tabebuia aurea & $0,76 \square$ \\
\hline
\end{tabular}

Tabela 3. Espécies de madeira identificadas para cada componente amostrado das embarcações tradicionais do baixo rio São Francisco, e respectivas densidades básicas.

Fonte: Elaborada pelos autores com base no acervo do Museu Nacional do Mar. Os dados de densidade básica foram obtidos de Carvalho (2003) $\diamond$, Instituto de Pesquisa Tecnológica do Estado de São Paulo (2003) $\boldsymbol{\Delta}$, Lorenzi (1992) $\square$, Lorenzi (2002) ○ e Mainiere \& Chimelo (1989)п.
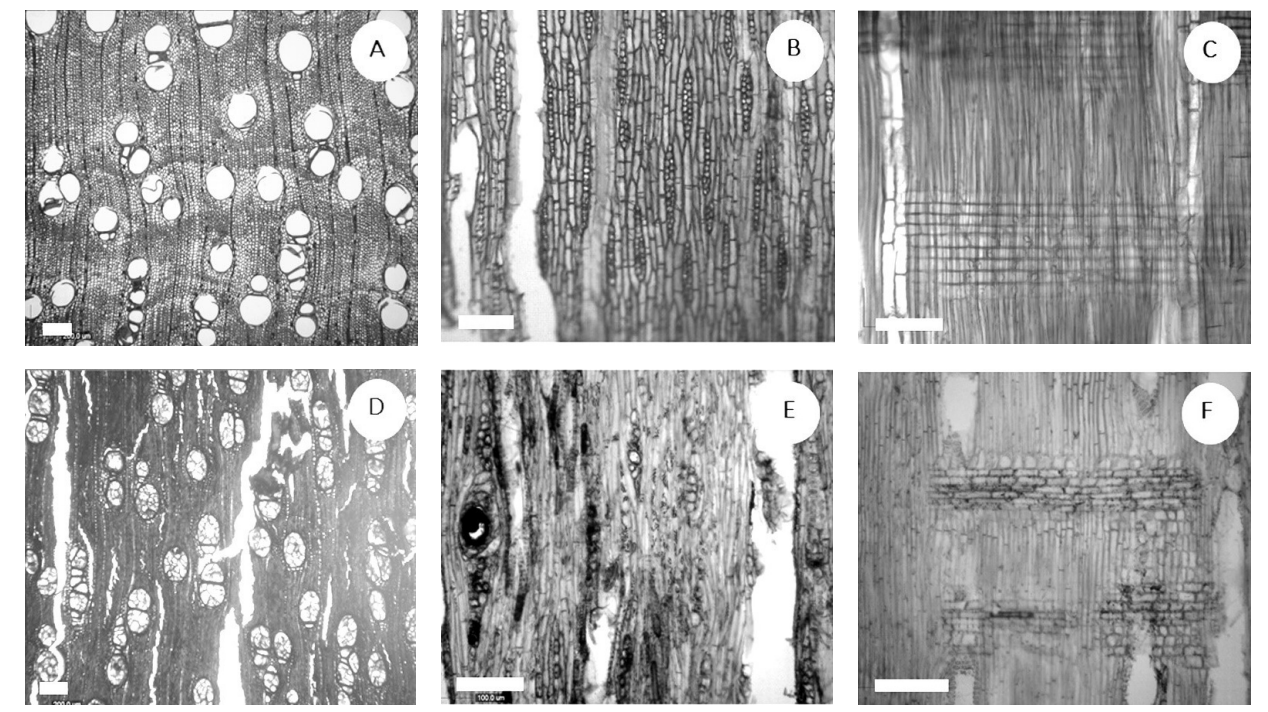

Fig. 3. Madeiras usadas na carpintaria naval de embarcações tradicionais do baixo rio São Francisco. 3A-C: Apuleia leiocarpa (amarelo). 3D-F: Astronium graveolens (guarita). 3A e 3D: secção transversal. 3B e 3E: secção longitudinal tangencial. 3C e 3F: secção longitudinal radial. 3A: porosidade difusa, vasos solitários e múltiplos radiais e parênquima axial aliforme e confluente. 3B: raios 1-2 seriados, parênquima axial e vasos estratificados. 3C: raios heterogêneos com corpos silicosos. 3D: porosidade difusa e vasos obstruídos por tilos. 3E: raios 1-3 seriados e canais radiais. 3F: raios heterogêneos com cristais prismáticos. Barras de escala: $200 \mu \mathrm{m}$.

Fonte: Elaborada pelos autores com base no acervo do Museu Nacional do Mar. 

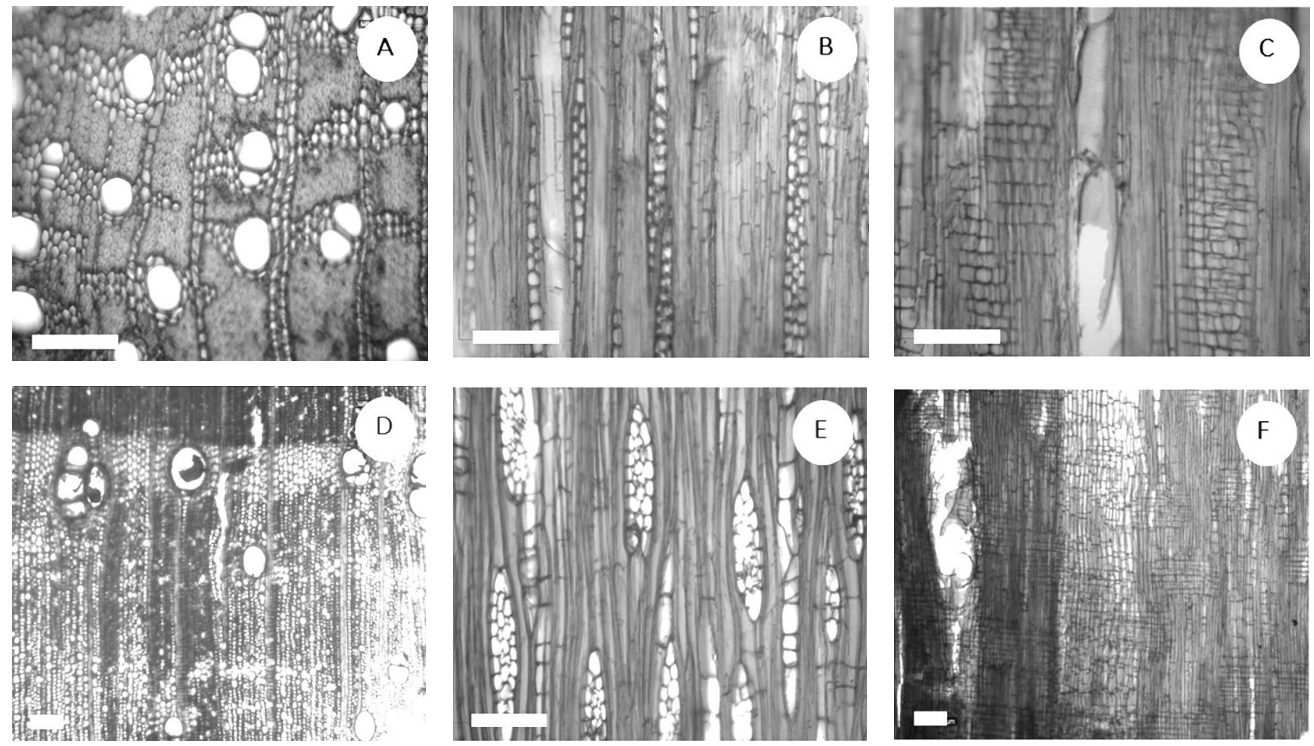

Fig. 4. Madeiras usadas na carpintaria naval de embarcações tradicionais do baixo rio São Francisco. 4A-C: Brosimum gaudichaudii (conduru). 4D-F: Dalbergia nigra (caviuna). 4A e 4D: secção transversal. 4B e 4E: secção longitudinal tangencial. 4C e 4F: secção longitudinal radial. 4A: porosidade difusa e parênquima axial aliforme e confluente. 4B: raios 1-3 seriados. 4C: raios heterogêneos. 4D: camada de crescimento distinta e porosidade difusa. 4E: raios 1-3 seriados e estratificados. 4F: raios heterogêneos e cristais prismáticos em câmaras do parênquima axial. Barras de escala: $200 \mu \mathrm{m}$.

Fonte: Elaborada pelos autores com base no acervo do Museu Nacional do Mar.
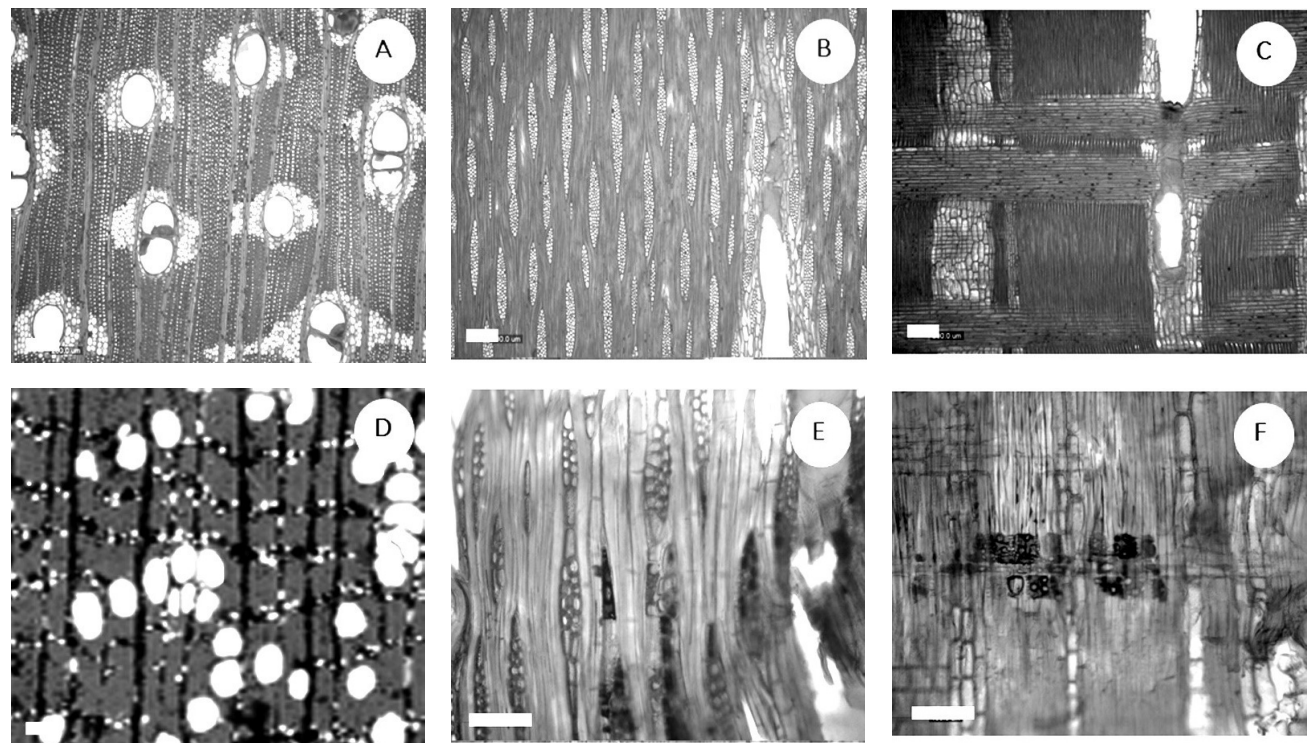

Fig. 5. Madeiras usadas na carpintaria naval de embarcações tradicionais do baixo rio São Francisco. 5A-C: Hymenaea courbaril (jataí). 5D-F: Manilkara dardanoi (maçaranduba). 5A e 5D: secção transversal. 5B e 5E: secção longitudinal tangencial. 5C e 5F: secção longitudinal radial. 5A: vasos solitários e parênquima axial vasicêntrico, aliforme e aliforme linear. 5B: raios 4-10 seriados, não estratificados. 5C: raios homogêneos. 5D: porosidade difusa e parênquima axial em linhas 1-3 células e reticulado. 5E: raios 1-3 seriados, localmente unisseriados. 5F: raios heterogêneos. Barras de escala: $200 \mu \mathrm{m}$.

Fonte: Elaborada pelos autores com base no acervo do Museu Nacional do Mar. 

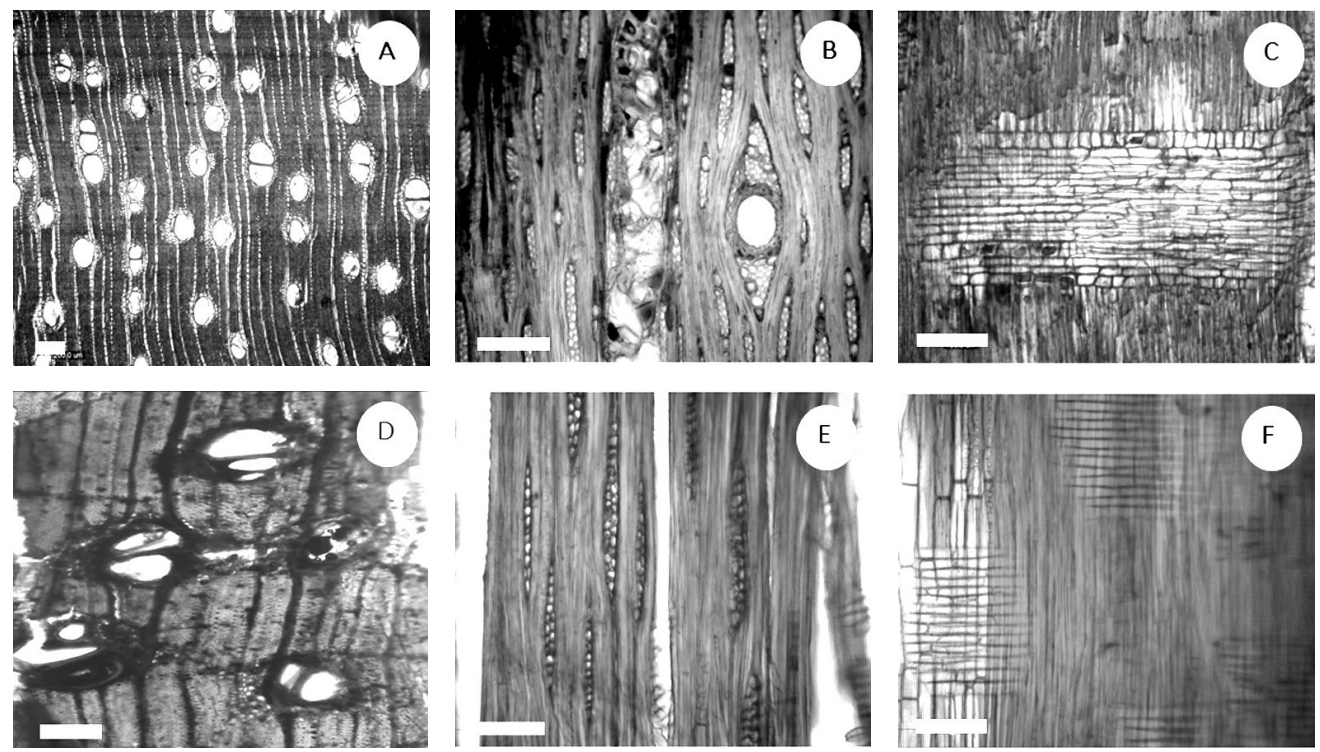

Fig. 6. Madeiras usadas na carpintaria naval de embarcações tradicionais do baixo rio São Francisco. 6A-C: Myracrodruon urundeuva (aroeira). 6D-F: Paubrasilia echinata (pau-d'arco). 6A e 6D: secção transversal. 6B e 6E: secção longitudinal tangencial. 6C e 6F: secção longitudinal radial. 6A: vasos solitários e múltiplos radiais obstruídos por tilos. 6B: raios $1-3$ seriados com canais radiais. $6 \mathrm{C}$ : raios heterogêneos com cristais prismáticos. 6D: porosidade difusa e parênquima axial vasicêntrico, aliforme e aliforme-losangular. 6E: raios 1-3 seriados. 6F: raios 1-3 seriados e cristais prismáticos em células subdivididas do parênquima axial. Barras de escala: $200 \mu \mathrm{m}$. Fonte: Elaborada pelos autores com base no acervo do Museu Nacional do Mar.
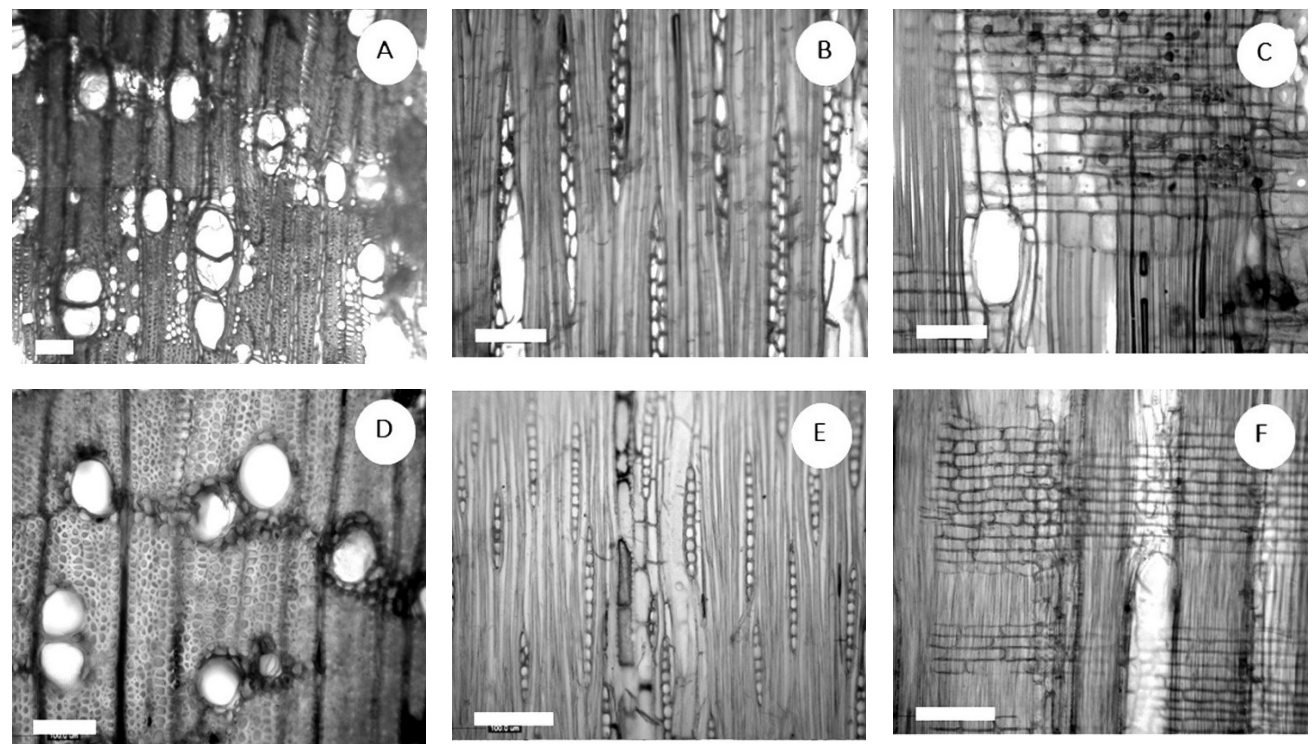

Fig. 7. Madeiras usadas na carpintaria naval de embarcações tradicionais do baixo rio São Francisco. 7A-C: Sextonia rubra (louro-rosa). 7D-F: Tabebuia aurea (ipê). 7A e 7D: secção transversal. 7B e 7E: secção longitudinal tangencial. 7C e 7F: secção longitudinal radial. 7A: vasos múltiplos radiais obstruídos por tilos. 7B: raios 1-3 seriados. 7C: raios heterogêneos e células oleíferas ou mucilaginosas associadas ao parênquima axial. 7D: porosidade difusa e paratraqueal aliforme, aliforme-losangular, confluente e unilateral. 7E: raios unisseriados. 7F: raios homogêneos irregularmente estratificados. Barras de escala: $200 \mu \mathrm{m}$.

Fonte: Elaborada pelos autores com base no acervo do Museu Nacional do Mar. 

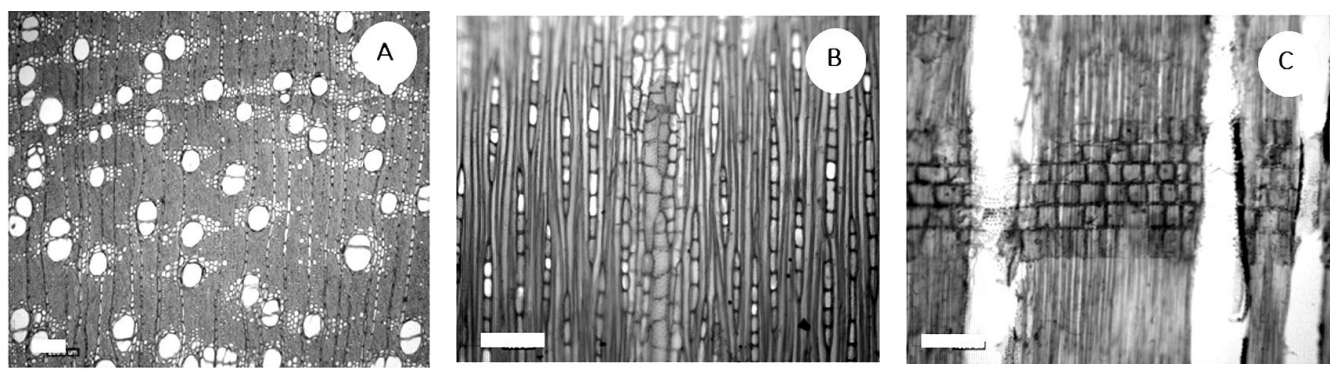

Fig. 8. Madeiras usadas na carpintaria naval de embarcações tradicionais do baixo rio São Francisco. 8A-C: Terminalia glabrencens (pequi). 8A: porosidade difusa e parênquima axial vasicêntrico, aliforme losangular e confluente em secção transversal. 8B: raios exclusivamente unisseriados em secção longitudinal tangencial. 8C: raios heterogêneos, formados apenas por células quadradas e eretas em secção longitudinal radial. Barras de escala: $200 \mu \mathrm{m}$.

Fonte: Elaborada pelos autores com base no acervo do Museu Nacional do Mar.

\section{Discussão}

Em sua totalidade, as espécies utilizadas na construção das embarcações do baixo rio São Francisco refletem a qualidade das madeiras no que diz respeito à sua resistência em condições naturais de contato direto e contínuo com a água fluvial, como uma combinação de propriedades físicas (ex.: alta densidade), anatômicas (ex.: espessura da parede das fibras) e químicas (ex.: óleo-resinas, gomas e outros depósitos) presentes no lenho (Savidge 2003).

A não constatação de madeiras preferenciais na carpintaria naval do baixo rio São Francisco é, sobretudo, transposta pela utilização de madeiras pesadas, que reúnem as características de resistência e durabilidade, assumindo, portanto, importante função estrutural nas embarcações (Couto 1985).

Informações sobre a distribuição geográfica natural das espécies identificadas permitem afirmar que os mestres fazedores de embarcações utilizaram matérias-primas extraídas de formações florestais pertencentes quase que integralmente aos ecossistemas inseridos no segmento baixo da bacia do rio São Francisco. Das onze madeiras identificadas, três espécies (D. nigra, M. dardanoi e P. echinata) são exclusivas da Floresta Pluvial Atlântica (Almeida Jr., 2015; Carvalho 1997; Lima 2017), três espécies (A. graveolens, H. courbaril e $T$. aurea) ocorrem tanto em Cerrado quanto em
Floresta Pluvial Atlântica (Lima \& Pinto 2015; Lohmann 2017; Silva-Luz \& Pirani 2015) e quatro espécies (A. leiocarpa, B. gaudichaudii, M. urundeuva e T. glabrencens) têm registro na Caatinga, no Cerrado e na Floresta Pluvial Atlântica (Lima 2015; Marquete \& Loiola 2015; Romaniuc Neto et al. 2015; Silva-Luz \& Pirani 2015). Apenas uma única espécie (S. rubra) ocorre exclusivamente na Amazônia (Quinet et al. 2015) e pode ter chegado na região do baixo rio São Francisco em virtude de este rio ter sido uma importante rota comercial no Brasil desde o século XVI - como verificado na cidade ribeirinha de Penedo/AL, que desde 1535 já recebia embarcações com mercadorias e passageiros vindos da Europa (Souza \& Caldas 2009) - sendo também o velho Chico uma rota estratégica da Coroa Portuguesa para o transporte de escravos, alimentos, ouro e outras mercadorias durante o período colonial (Camelo Filho 2005).

Estudos com madeiras históricas utilizadas na produção de diferentes objetos culturais no Brasil têm mostrado o uso de uma diversa gama de espécies de madeiras, muito embora alguns táxons apresentem certa prevalência de uso (Melo Jr. 2012b; Melo Jr. \& Boeger 2015; Melo Jr. et al. 2013). A utilização da madeira de $D$. nigra tem sido registrada, devido à sua exuberante coloração, não somente na carpintaria naval (Gonzaga 2010), mas na produção de mobiliário de luxo (Melo Jr. \& Boeger 2015), estruturas construtivas de 
habitações coloniais (Melo Jr. 2012a) e instrumentos musicais (Angyalossy, Amano \& Alves 2005), além de ter sido explorada comercialmente pelos portugueses na Europa (Gasson et al. 2010). Outra espécie amplamente usada é M. urundeuva, com registro de uso desde a pré-história brasileira como combustível de fogueiras paleoíndias (Melo Jr. \& Magalhães 2015), como estruturas construtivas de igrejas do período colonial (Andreacci \& Melo Jr. 2011) e como embarcações (Gonzaga 2010).

A carpintaria naval da região Nordeste do Brasil engloba o uso de aproximadamente trinta espécies de madeiras (Gonzaga 2010), dentre as quais o angelim vermelho e amarelo, o ipê, o jenipapo, o jequitibá, o louro, a sucupira, o oiti, o pau-brasil, a pindaíba, o potumuju, o tapinhoã e o vinhático já eram madeiras exploradas pela sociedade colonial desde o século XVI para abastecer os estaleiros de Salvador e Lisboa (Dias 2010) ou para reparar navios que atracavam na costa brasileira (Hutter 1986). Muito possivelmente, o uso massivo de determinadas espécies de madeira na carpintaria naval contribuiu com a redução das suas populações naturais (ex.: P. echinata, em perigo de extinção) (Conselho Nacional de Conservação da Flora 2017), o que pode ter sido intensificado pelos decretos reais que asseguravam à Coroa Portuguesa, de maneira exclusiva, a exploração de certas espécies de madeiras brasileiras, como o olandi (Calophyllum brasiliensis, Calophyllaceae), o tapinhoã (Mezilaurus navalium, Lauraceae), a itaúba-preta (Mezilaurus itauba, Lauraceae) e o jatobá (Hymenaea stignocarpa, Fabaceae)
(Gonzaga 2010), em detrimento do esgotamento florestal de Portugal desde o século XII (Cabral 2008).

Parece que a oferta de recursos florestais em maior escala, para além das suas propriedades físico-mecânicas, é um fator que implicou a seleção de madeiras na carpintaria naval do baixo São Francisco, o que guarda certa similaridade com a construção de navios romanos que conjugava até sete espécies de madeiras (Capretti et al. 2008; Giachi et al. 2003).

Por outro lado, a construção de embarcações tradicionais é, em especial no território brasileiro, marcada pela herança de saberes de várias etnias indígenas sobre o conhecimento tecnológico acerca dos recursos florestais e de seu manejo, por meio de trocas culturais que perpetuam os saberes orais dos antepassados, atravessam gerações e imprimem à construção de embarcações tradicionais um rico significado cultural que integra pessoas e árvores na paisagem do rio São Francisco.

\section{Agradecimentos}

Ao Instituto de Pesquisas do Jardim Botânico do Rio de Janeiro pela oferta do pósdoutoramento. Ao Programa de Qualificação Docente da Universidade da Região de Joinville pelo auxílio à realização da pesquisa. Ao Museu Nacional do Mar e toda a sua equipe pela oportunidade de aprendizado, pelos saberes compartilhados, pelo acesso ao acervo museológico e pelo constante apoio prestado.

MELO JÚNIOR, J.C.F.; BARROS, C.F. Historical timbers in traditional vessels of the lower São Francisco River. R. Museu Arq. Etn., 28: 109-123, 2017.

Abstract: Traditional Abstract: boats are directly linked to the history of the São Francisco river and its riverine communities, one of the largest navigable rivers that allowed the colonization of northeastern Brazil. This study is aimed to identify the wood used in the construction of boats from the lower São Francisco river, and generates subsidies to better understand the relations of use of forest resources destined to traditional naval carpentry. Four boats were studied belonging to the museum collection of the National Sea Museum, São Francisco do Sul, Santa Catarina. The collection of historical timber 
was performed with the aid increment borer for subsequent production of histological slides and anatomical description. The identification of the timber was conducted by comparison with reference collection. Eleven timber species were identified in the construction of the boat's components. They are: Apuleia leiocarpa (Fabaceae), Astronium graveolens (Anacardiaceae), Brosimum gaudichaudii (Moraceae), Dalbergia nigra (Fabaceae), Hymenaea courbaril (Fabaceae), Manilkara dardanoi (Sapotaceae), Myracrodruon urundeuva (Anacardiaceae), Paubrasilia echinata (Fabaceae), Sextonia rubra (Lauraceae), Tabebuia aurea (Bignoniaceae) and Terminalia glabrencens (Combretaceae). The knowledge about the timber and their technological use provide to the construction of traditional boats a rich cultural meaning that integrates people and trees in the landscape of the São Francisco river.

Keywords: Cultural heritage; Naval heritage; Wood anatomy; Forest resources; Velho Chico.

\section{Referências bibliográficas}

Almeida Jr., E.B. 2015. Manilkara dardanoi. Jbrj.gov, [S.l.]. Disponível em: <https://goo.gl/bq2hW9 $>$. Acesso em: 8/3/2018.

Andreacci, F.; Melo Jr., J.C.F. 2011. Madeiras históricas do barroco mineiro: interfaces entre o patrimônio cultural material e a anatomia vegetal. Rodriguésia 62: 241-251.

Angyalossy, V.; Amano, E.; Alves, E. S. 2005. Madeiras utilizadas na fabricação de arcos para instrumentos de corda: aspectos anatômicos. Acta Botanica Brasilica 19 (4): 819-834.

Arruda, D.M.; Schaefer, C.E.G.R.; Moraes, M.T.B. 2005. Relações entre atributos do solo e vegetações da região ecotonal do médio rio São Francisco, Brasil. Revista Brasileira de Ciências do Solo 39: 1524-1532.

Cabral, D.C. 2008. Floresta, política e trabalho: a exploração das madeiras-de-lei no Recôncavo da Guanabara (1760-1820). Revista Brasileira de História 28 (55): 217-241.

Camelo Filho, J.V. 2005. A dinâmica política, econômica e social do rio São Francisco e do seu vale. Revista do Departamento de Geografia 17: 83-93.
Capretti, C. et al. 2008. The characterization of waterlogged archaeological wood: the three roman ships found in Naples (Italy). Archaeometry 50: 855-876.

Carvalho, P.E.R. 2003. Espécies arbóreas brasileiras. Embrapa Florestas, Colombo. 1039 p.

Carvalho, A.M. 1997. A synopsis of the genus Dalbergia (Fabaceae: Dalbergieae) in Brazil. Brittonia 49 (1): 87-109.

Conselho Nacional de Conservação da Flora. 2017. Lista vermelha. Jbrj.gov, [S.1.]. Disponível em: <https://goo.gl/ppRhsj>. Acesso em: 8/3/2018.

Couto, R.G. 1985. Embarcações típicas do Brasil. Salvador: Index Produções Culturais. 135 p.

Détienne, P.; Jacquet, P. 1983. Atlas d'identification des bois de l'Amazonie et des régions voisines. Centre Téchnique Forestier Tropical, Nogent-sur-Marne. $640 \mathrm{p}$.

Dias, M.H. 2010. A floresta mercantil: exploração madeireira na capitania de Ilhéus no século XVIII. Revista Brasileira de História 30 (59): 193214. 
Gasson, P. et al. 2010. Wood identification of Dalbergia nigra (Cites Appendix I) using quantitative wood anatomy, principal components analysis and naive Bayes classification. Annals of Botany 105 (1): 45-56.

Giachi, G. et al. 2003. The wood of "C"and "F" Roman ships found in the ancient harbor of Pisa (Tuscany, Italy): the utilization of different timbers and the probable geographical area which supplied them. Journal of Cultural Heritage 4 (4): 269-283.

Godinho, H.P.; Godinho, A.L. (Orgs.). 2003. Águas, peixes e pescadores do São Francisco das Minas Gerais. PUC, Belo Horizonte. 468 p.

Gonzaga, A.L. 2010. Análise especializada sobre madeiras utilizadas na carpintaria naval. Iphan, Brasília. 98 p.

Hutter, L.M. 1986. A madeira do Brasil na construção e reparo de embarcações. Revista do Instituto de Estatística Brasileira 26: 47-64.

Iawa Committee. 1989. List of microscopic features for hardwood identification. Iawa Bulletin 10: 219-332.

Instituto de Pesquisa Tecnológica do Estado de São Paulo. 2003. Madeiras: uso sustentável na construção civil. IPT, São Paulo. 59 p.

Kohler, H.C. 2003. Aspectos geoecológicos da bacia hidrográfica do São Francisco (primeira aproximação na escala 1:1 000 000). In: Godinho, H.P.; Godinho, A. L. (Orgs.). Águas, peixes e pescadores do São Francisco das Minas Gerais. PUC Minas, Belo Horizonte, 25-35.

Kraus, J.E.; Arduin, M. 1997. Manual básico de métodos em morfologia vegetal. Edur, Seropédica. $198 \mathrm{p}$.

Lima, H.C. 2015. Apuleia leiocarpa. Jbrj.gov, [S.1.]. Disponível em: <https://goo.gl/rtq7i7>. Acesso em: $8 / 3 / 2018$.

Lima, H.C. 2017. Paubrasilia. Jbrj.gov, [S.1.]. Disponível em: <https://goo.gl/3Vxm4n>. Acesso em: 8/3/2018.
Lima, H.C.; Pinto, R.B. 2015. Hymenaea courbaril L. Jbrj.gov, [S.l.]. Disponível em: <https://goo.gl/ BDwfck >. Acesso em: 8/3/2018.

Lohmann, L.G. 2017. Tabebuia aurea. Jbrj.gov, [S.l.]. Disponível em: <https://goo.gl/nKZLWC >. Acesso em: 8/3/2018.

Lorenzi, H. 1992. Árvores brasileiras: manual de identificação e cultivo de plantas arbóreas nativas do Brasil. Plantarum, Nova Odessa, v. 1, 352 p.

Lorenzi, H. 2002. Árvores brasileiras: manual de identificação e cultivo de plantas arbóreas nativas do Brasil. v. 2. Plantarum, Nova Odessa, v. 2, $368 \mathrm{p}$.

Mainieri, C.; Chimelo, J.P. 1989. Fichas de características das madeiras brasileiras. IPT, São Paulo. 418 p.

Marquete, N.; Loiola, M.I.B. 2015. Terminalia glabrescens. Jbrj.gov, [S.l.]. Disponível em: <https://goo.gl/u2ypGy>. Acesso em: 8/3/2018.

Melo Jr., J.C.F. 2012a. Anatomia de madeiras históricas: um olhar biológico sobre o patrimônio cultural. Univille, Joinville. 132 p.

Melo Jr., J.C.F. 2012b. Aspectos anatômicos de madeiras históricas do período colonial do nordeste de Santa Catarina: elementos para conservação do patrimônio cultural. Revista Confluências Culturais 1: 70-84.

Melo Jr., J.C.F.; Amorim, M. W.; Silveira, E. R. 2014. A xiloteca (coleção Joinvillea - JOIw) da Universidade da Região de Joinville. Rodriguésia 65 (4): 1057-1060.

Melo Jr., J.C.F; Boeger, M.R.T. 2015. The use of wood in cultural objects in 19th Century Southern Brazil. Iawa Journal 36 (1): 98-116.

Melo Jr., J.C.F.; Gomes-Silva, E.; Ouriques, M. M. 2013. Aspectos anatômicos e etnobotânicos de artefatos zoomórficos em madeira Guarani-Mbyá do aldeamento Pindoty, Araquari/SC. Ciência e Cultura 9: 47-57. 
Melo Jr., J.C.F.; Magalhães, W.L.E. 2015. Antracologia de fogueiras paleoíndias do Brasil central: considerações tecnológicas e paleoetnobotânicas sobre o uso de recursos florestais no abrigo rupestre Lapa do Santo, Minas Gerais, Brasil. Antipoda Revista de Antropologia y Arqueologia 22: 137-161.

Montenegro, S.C.S.; Nordi, N.; Marques, J.G.W. 2001. Contexto cultural, ecológico e econômico da produção e ocupação dos espaços de pesca pelos pescadores de pitu (macrobrachium carcinus) em um trecho do Baixo São Francisco, AlagoasBrasil. Interciencia 26 (11): 535-540.

Museu Nacional do Mar. 2008. Cadastramento de embarcações tradicionais brasileiras (litoral de Santa Catarina). Memorial descritivo. Iphan, processo $\mathrm{n}^{\circ}$ 01450.015660/2009-04, São Francisco do Sul.

Museu Nacional do Mar. 2010. Arrolamento do acervo do Museu Nacional do Mar: fichas cadastrais. MNM, São Francisco do Sul. 316 p.

Navios \& Portos. 2016. História da marinha mercante brasileira. Navios \& Portos, [S.1.]. Disponível em: $<$ https://goo.gl/k2BV5H>. Acesso em: 8/3/2018.

Paiva, J.G.A. et al. 2006. Verniz vitral incolor 500: uma alternativa de meio de montagem economicamente viável. Acta Botanica Brasilica 20: 257-264.

Paiva, M. P. 1982. Grandes represas do Brasil. Editerra, Brasília. 304 p.

Pardal, P. 1979. Carrancas do São Francisco. Funarte, Rio de Janeiro. $32 \mathrm{p}$.
Quinet, A. et al. 2015. Sextonia rubra. Jbrj.gov, [S.l.]. Disponível em: <https://goo.gl/MyqQ5H>. Acesso em: 8/3/2018.

Romaniuc Neto, S. et al. 2015. Brosimum gaudichaudii. Jbrj.gov, [S.1.]. Disponível em: <https://goo.gl/UHwTyV>. Acesso em: 8/3/2018.

Savidge, R.A. 2003. Tree growth and wood quality. In: Barnett, J.R.; Jeronimidis, G. (Eds.). Wood quality and its biological basis. Blackwell, Oxford, 1-29.

Silva, I.R.L. 2013. Vamos navegar! A construção artesanal de canoas na cidade de Pão de Açúcar: arte e tradição pelas mãos dos mestres fazedores de canoas. In: Anais do III Seminário de Estudos Culturais, Identidades e Relações Interétnicas, 2013, São Cristóvao (CD-ROM).

Silva-Luz, C.L.; Pirani, J.R. 2015. Anacardium L. Jbrj.gov, [S.l.]. Disponível em: <https://goo.gl/ QBLMcK>. Acesso em: 8/3/2018.

Souza, R.C.A.; Caldas, A.S. 2009. Viagem ao São Francisco. Unifacs, Salvador. 64 p.

Valencio, N.F.L.S. et al. 2003. A precarização do trabalho no território das águas: limitações atuais ao exercício da pesca profissional no alto-médio São Francisco. In: Godinho, H.P.; Godinho, A.L. (Orgs.). Águas, peixes e pescadores do São Francisco das Minas Gerais. PUC, Belo Horizonte, 423-446.

Wheeler, E.A. 2011. Inside Wood: a web resource for hardwood anatomy. Iawa Journal 32 (2): 199-211. 